\title{
La fantástica ventura de Tomás Carrasquilla
}

Fecha de recepción: 12 abril de 2010

Fecha de aprobación: 1 junio de 2010

Un modo de parodiar y dialogar entre la noveleta En la diestra de Dios padre. Cuento de Señá Ruperta, un gran poema de León de Greiff y la obra del gran ilustrador y panida Mexía.

\section{Miguel Ignacio Salazar Holguín}

misalaza@poligran.edu.co

Politécnico Grancolombiano

\section{Reseña de autor}

Traductor profesional del inglés al español, profesor-investigador en el área de literatura con énfasis en lectoescritura, tiene particular interés en la traductología, en estudios culturales, en teoría y análisis medial. Cuenta con experiencia en el campo de la educación, la traductología y la realización-locución audiovisual multiformato.

Tomás Carrasquilla Naranjo (Santo Domingo, Antioquia, 1858, Medellín, 1940), más que un exponente de la novela regionalista y costumbrista americana, es pionero de la literatura realista (Menton, 1964). A partir de la transcripción -travestie acentuada en la tercera sílaba en inglés y francés- de la oralitura folclórica de En la diestra de Dios Padre: cuento de Señá Ruperta, Carrasquilla es reconocido como el gran difusor y relator insigne de las breñas antioqueñas, y no el costumbrista tan angostamente reseñado en textos escolares y otras antologías de dudosa procedencia.

Este artículo disertará y cuestionará la importancia de este autor, no sólo como progenitor del regionalismo (Levy, 1958), sino como quien se toma muy en serio el oficio de novelista y logra ir más allá de las fronteras, hacia el retrato de su parroquia; para tal fin, se
Tomás Carrasquilla Naranjo (1858-1940) has been typified in some extent as a Folk-literature writer in Latin America. The legitimate purpose of this article is to consider him as a true and brave pioneer of our Cosmopolitan and Realistic literature, likewise.

His timeless substance and legacy has been recorded through his celebrated parody remake forgery, or even better, transvestitenouvelle adapted many times into plays and theatre representations: En la diestra de Dios Padre: cuento de Señá Ruperta. It still arouses fascination among many fruitful theotetical approaches and various critical workpieces.

A backing thesis to this dissertation is provided by Johann Huizinga in his Homo Ludens. He says that human beings have developed play as almost his/her truest and pristine tool-omen-, thanks to which poetry 
propone leer claves arquetípicas inscritas en este cuento. El texto, junto con su vida, emanan un espíritu universal sin trascender la geografía íntima y física de su terruño, salvo muy pocas veces a lugares cercanos de su patria.

Se expondrán aspectos sobresalientes de la sustancia atemporal de esta parodia espiritual, sustentada por la aguda tesis de Huizinga: la lúdica marca la génesis no sólo de la poesía y el derecho, sino de la cultura misma.

Asimismo, esta disertación se basará en atisbos sobre cómo José Félix Mejía Arango (1895-1978), arquitecto de profesión, también fue un gran dibujante y caricaturista que entabló una amistad singular, fantástica y perenne con el cuñado de su tío Claudino.

Éste último, fundó la revista Panida con varios antioqueños ilustres, entabló una especial y afectuosa amistad con el novelista del pueblo de las tres efes y hace parte de La vanguardia clandestina, enclavada entre el periodo de la Academia y la aparición de los Bachués.

Política, lúdica, y literariamente -el humor serio y festivo-, estos dos seres revisten gran importancia, pues antes que antioqueños y colombianos - un mero accidente-, son dignos representantes del arte universal de una de las regiones del globo más susceptible al juego creativo.

\section{Palabras clave}

Arquetipo, juego serio, lúdica, mojiganga, palimpsesto, momo(s), realismo. and even the structuring of law system -jurisprudence-, occured.

Altogether, this article favors ludens factor and, inherently, the relocalization of Tomás Carrasquilla, amongst the greatest hilarious and enduring Latin American Belles lettres champions.

José Félix, Pepe Mexía, besides, has been a long-forgotten -younger and nephew of TcN's brother-in-law, Claudino Arangoarchitect, caricaturist and artist, born also in Antioquia, whom in one hand has been refer to in this dissertation and thus, typifies on one hand the progressive and metamorphing archetype of main character, Peralta, as typical Andean "picaresque".

On the other hand, Mexía as an urban artist, amongst digging on their sound, creative and humorous social surrounding, is an emblematic figure of a generation. "Such is life in Colombia!".

\section{Keywords:}

Archetype, Serious Game, Ludens, Mojiganga, Palimpsest, Momo, Realism. 


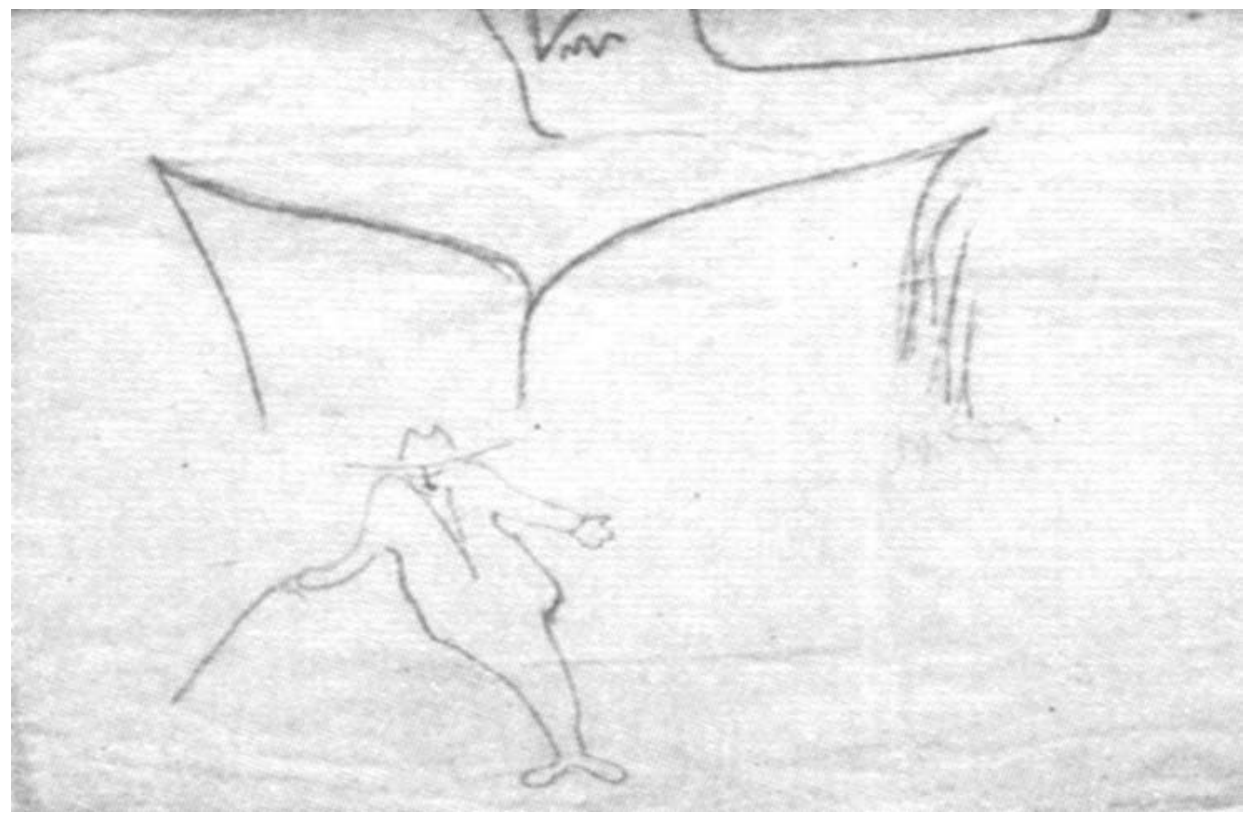

(CPepe Mexía. Retrato Núm. 9 ("Tomás Carrasquilla"). Lápiz sobre papel mantequilla (detalle), $21 \times 28 \mathrm{~cm}$.

Este absoluto desconocimiento de las cosas satisface al colombiano auténtico, cuya fantasía aventurera, que no conoce ninguna barrera, puede idearse los cuentos más inverosímiles, sin tener nada que temer, sin inventar algo que parezca increible a sus paisanos. Reiss, Wilhelm (1994).

On Pembroke Road, look out for my ghost, disheveled with shoes untied, playing through the railings with little children, whose children have long since died.
Si alguna remota vez visitares Santo Domingo en alguna calle'e mi poblacho de las tres efes: feo, frio y faldudo. ¡Virgen Madre de la Santísima Trinidá échale ojo a ese mi ser fantasmal, andrajoso y con los zapatos deshechos, por entre verjas jugando con mocosos, cuyos niños hace rato yacen... difuntos. If ever you go to Dublin Town. Patrick Kavanagh (1904-1967) ${ }^{1}$ 


\section{Pues, "asíes la vida en Colombia"}

A don Tomás Carrasquilla Naranjo bien se le puede considerar un gran precursor de la novela realista americana (Menton, 1964), así como un gestor de un tipo de literatura folclórica con visos universales -en algunos de sus cuentos con mayor ahínco- del más genuino y legítimo sabor propio de su tierra; sin que sea necesariamente el representante del costumbrismo o de una literatura regionalista, ni tampoco el émulo de los costumbristas peninsulares del siglo antepasado, como Emilia Pardo Bazán o José María de Pereda.

Empero, Kurt L.Levy(1917-2000), biógrafo del novelista y carrasquillólogo canadiense, lo llama en su estudio "genitor" de la literatura regionalista. Sin embargo, esto no basta para atrapar la quintaesencia de su legado literario, filosófica y humanamente apreciados. Miremos pues algunos de sus modos y rasgos más sobresalientes en breves ráfagas de su vida y en especial, en este relate, nouvelle o noveleta muy teatralizada $\mathrm{y}$ emblemática: En la diestra de Dios Padre: cuento de señá Ruperta.

El sacerdote Enrique Pérez Arbeláez (1896-1972) -fundador del jardín Botánico José Celestino Mutis, en Bogotá- en su libro Plantas útiles de Colombia, y al mejor estilo del sabio gaditano que le da nombre a ese refugio de paz en la capital del país (p. 618), lanza hacia los años cincuenta la perla que encabeza este apartado, cargada de ironía: una sabia imprecación, probable y subterráneamente dirigida a las autoridades agrícolas colombianas por su desidia y miopía, incluso hoy reinantes, al no contrarrestar las ya cuantiosas importaciones de pimienta negra para dicha época, con el fomento de su cultivo y explotación en suelo colombiano (p. 618).

Para efectos de este breve recorrido crítico, se llamará la atención sobre la multiplicidad que caracteriza no sólo al suelo sino a las manifestaciones literarias, musicales, humorísticas y de las artes nacionales en general; es decir, tanto a obras materiales como inmateriales aún vivas en la memoria, gracias a la tradición oral, que aún permanecen inexploradas.

Quedan por revisar los accidentes y características sorprendentes de nuestra lengua, nuestro vernáculo idioma castellano aclimatado y apropiado en suelo colombiano, que cambia según la región que lo apropia y que es parte orgánica y consubstancial de un legado popular, de su ser más íntimo, de nuestra identidad recóndita.

Rufino J. Cuervo, el hermano de Ángel, más escritor de costumbres que sabio gramático, flemático y también cervecero bogotano, estaba radicado en París en la segunda mitad del siglo xix. Sobre esa profesión de amor a la lengua opinaba que 
Mirar por la lengua vale para nosotros tanto como cuidar los recuerdos de nuestros mayores, las tradiciones de nuestro pueblo y las glorias de nuestros héroes; $y$ cuando varios pueblos gozan del beneficio de un idioma común, propender a su uniformidad es avigorar sus simpatías y relaciones, hacerlos uno solo.

(Cuervo, 1954)

Disentimos de su opinión, por demás idealista. Aquello de la supuesta unidad tan característica de su candorosa ingenuidad y castidad, propia del centralismo regenerador, hoy día es difícil admitir.

Con su singular estrategia de escritura, Carrasquilla aboga por algo mucho más loable y razonable: la construcción plena de la identidad, del reconocimiento, la revaloración y el reencuentro con la manera natural del habla popular - por la geografía de Antioquia, en este caso-, y su transcripción al papel sin comillas, sino como un acto natural y sin precedentes, como un acto de apropiación de esa fisonomía suculenta, aromática y acorde con la condición sociocultural de todos nosotros, colombianos que como sujetos hablantes a veces perdemos la noble ocasión de mirarnos, incluso doscientos años después de la gesta independentista.

\section{Tomás Carrasquilla: precoz pepo o cachaco, gran averigüietas y sopero de su sociedad}

Don Tomás Carrasquilla nació en Santo Domingo, Antioquia, el 17 de enero de 1858 y murió en Medellín, el 19 de diciembre de 1940. Es hijo del hogar constituido por don Rafael Carrasquilla y doña Ecilda Naranjo, era una familia acomodada, como el mismo lo confiesa en su excelente Autobiografía de 1914, escrita por petición de los redactores de El Gráfico.

En primera instancia, se dedicó a la sastrería, luego estudió Humanidades durante dos años en la Universidad de Antioquia y algo de Abogacía también en Medellín. En sus inicios como escritor, utilizó el seudónimo anagramático Carlos Malaquita.

Regresó muy pronto a su pueblo, a las breñas de su parroquia, para dedicarse a escribir y a observar el comportamiento, las costumbres, las fábulas y los mitos de los de su tierra.

Sopero, averigüetas y maestro de lo cotidiano, este cronista fascinante y fisgón de lo que acontece en su tierra, entre los de su poblacho, vive metido entre el pueblo, incluso en las entrañas de la tierra. Trabajó en la minería aurífera, entre otros oficios administrativos, ocupó el de despensero de la mina de San Andrés -corregimiento de Argelia de 
María, Antioquia-, durante cinco años. Con razón Lleras Camargo dijo que él era el auténtico sobreviviente del Siglo de Oro español.

Luego, como requisito de admisión e impulsado por el grupo de El Casino literario, publicó su primer cuento: Simón el mago, escrito probablemente hacia 1892.

Tras la famosa querella sobre la existencia de material novelable en Antioquia, surgió una novela que Carrasquilla revisó y reelaboró en varias oportunidades: Frutos de mi tierra, que tuvo otros títulos entre los que cabe destacar, $J a-$ mones y solomos, Jamones y tocinos y Tocinos y tasajos. Un fragmento de esta novela apareció por primera vez en la Revista Santandereana, como Jamones y solomillos: fragmento de una novela inédita, el 12 de diciembre de 1891; y fue publicada en su totalidad en 1896.

El título del fragmento da forma al carácter de sus protagonistas, los Alzate, quienes con esta marca de ascenso social, connotan el carácter porcino -aún no existía el virus de influenza tipo A- sugerido en el título, opuesto al Escandón, que sí posee un cierto abolengo criollo.

Seymour Menton (1964) considera que ésta es más que una simple novela regionalista o costumbrista, y la eleva a la condición de gran novela en el marco del realismo hispanoamericano. Ésta marca un hito en las letras hispánicas y universales por trascender en forma y estilo, la simple comarca antioqueña, rural y americana.
Algunos intelectuales antioqueños tuvieron una participación activa en las tertulias que aparentemente se dan entre 1890 y 1892, en el Casino Literario o en la Tertulia Literaria.

Otro grupo célebre fue La Biblioteca del Tercer Piso, centro cultural y educativo del que Carrasquilla fue vicepresidente, además fue juez municipal en Santo Domingo. Entre otros, sus colegas fueron Francisco de Paula Rendón y Carlos Eugenio Restrepo.

Según éste último, ex presidente de la República de Colombia, y Jorge Alberto Naranjo, pariente y amigo, la discusión sobre la existencia de material novelable en Antioquia dio origen al proyecto de escribir una novela y de hacerse escritor definitivamente.

Carrasquilla envió su Autobiografía a los redactores del periódico E1 Gráfico, en 1914. Sin duda, para Colombia éste es uno de los escritores más importantes de todas las épocas.

Entre 1896 y 1899 publicó Frutos de mi tierra (1896), Simón el mago (1896), En la diestra de Dios Padre (1897), Herejias (1897), Blanca (1897), Dimitas Arias (1897), El ánima sola (1898) y, en 1899, San Antoñito, El baile blanco y Luterito, en los mismos periódicos.

Después publicó muchos otros títulos: El Padre Casafús (1899), A la plata (1901), Salve Regina (1903), Entrañas de un niño y Homilias (1906), Grandeza (1910) y El rifle (1915), de inmenso candor y gran incursión en la psicología 
infantil. En 1926 terminó La Marquesa de Yolombó, publicada por entregas.

En 1930, recurre al dictado para escribir la trilogía Hace tiempos, memorias de Eloy Gamboa, pues estaba totalmente ciego. Recobró la vista parcialmente, gracias a una cirugía del ojo izquierdo practicada por un sobrino médico.

En 1935 se le confiere La Cruz de Boyacá y aparecen Por aguas y pedrejones y Por cumbres y cañadas, las dos primeras partes de la mencionada trilogía. Falleció por causa de una gangrena en una pierna, en el Hospital de San Vicente de Paúl en Medellín, en 1940.

Sin duda el viejo Carrasco deshilvana, amén de desentrañar con gracia suprema la sustancia atemporal de su parodia -clasificable en el género "de viejas y de niños", según la completa sistemática de M. Chevalier-, un gran tesoro aurífero de boca de Teresa Roldán o de otra trovadora llamada tal y como reza en el subtítulo, señá Ruperta, tal vez conocida como la Perrucha, según el cruce de cartas rico y agudo con el poeta caldense Maximiliano Grillo (Marmato, Caldas 1868 - Bogotá, 1949) o Grillito, como fue tratado cariñosamente.

Carrasquilla reelabora y trascribe un canto creativo-lúdico como homenaje a los de su tierra, y da claves para leer e interpretar la visión de mundo impregnada en su autoría -yo narrador-, un modo y un arquetipo de gran apertura intelectual y espiritual, al hacer hablar y jugar a unos personajes populares -el pícaro arriero-y a seres mítico-mágicos -Jesús o Santa Teresa-, en su entorno sociocultural y natural.

El habla vernácula y popular que Carrasquilla nos trascribe y pinta, en contraposición a la lengua oficial, está revestida de un profundo sentido poético.

Este pepo, lechuguino o cachaco, muy sopero y averigüetas, aparte de ser el vicepresidente de la tertulia E1 segundo piso, en su Santo Domingo natal, obtuvo un único galardón literario en vida, el Premio Nacional de Literatura y Ciencias José María Vergara y Vergara $^{2}$, conferido por la Academia Colombiana de la Lengua, en sesión solemne del 19 de marzo de 1936, en Bogotá.

Como gran parte de su obra va más allá del ámbito temporal y corre como hito latinoamericano mayor, este artículo es un homenaje al gran cultor de las letras, humorista y demiurgo satírico e irónico de Colombia, quien al parecer se sentía más cómodo en los riscos abismales de su Estado Federado que entre fríos seguidores del centralismo en la capital del país -envueltos en capas negras, a la española-, justo en ese momento posfederalista, decisivo para el inicio del gran ascenso industrial y de la modernización educativa y agrícola de Antioquia.

Sus jurados fueron los insignes escritores colombianos Baldomero Sanín Cano, Eduardo Zalamea y Antonio Gómez Restrepo. 
Se pretende entonces, descubrir y reconocer a este gran escritor de las letras y las breñas colombianas de una manera distinta a su imagen como monumento estático de piedra, bronce o mármol -entre otras, ¿dónde está esa escultura magnífica?- o como el celebradísimo y enorme autor -fue alto en todo el sentido de la palabra, y muy cabecipelón para impedir que se le tomara del pelo-; sino como un auténtico novelista de oficio, con muy buen caudal narrativo, decoro y elegancia, tal vez en el sentido en el que hace honor no solo a nuestra memoria americana sino también a ese otro grande, José Martí.

$\mathrm{Su}$ gran valor estético es intachable y reside en el alma infantil -narrativa sicológica- y tanto como en la prosa narrativa histórica, representada por La marquesa de Yolombó, como en sus ensayos filosóficos Homilias I y II y sus hermosas crónicas y cronicones, entre otros perfiles multifacéticos y escritos periodísticos; $y$, por supuesto, en el gran tesoro de sus grandes reflexiones estéticas, presentes en su cuantiosa literatura epistolar.

\section{¿Es posible considerar a Carrasquilla como un autor universal?}

Carlos Sánchez Lozano (1996) ${ }^{3}$ cuestiona la posible inclusión de la obra carras-

http://www.lablaa.org/blaavirtual/literatura/carrasqu/carras $1 . h t m$ quillana en una opus universal y se refiere al asunto destacable de la literatura posterior -conocido como el boom- en los siguientes términos:

Sólo una posterior catarsis permitirá que los problemas de la novela regionalista - uso de jergas locales, intenciones de hacer sociología, exposición de tesis políticas, configuración de personajes caricaturescos- sean enfrentados y asumidos por una nueva generación de novelistas pertenecientes al realismo cosmopolita o "realismo crítico", como lo llamó el crítico uruguayo Ángel Rama: Machado de Assis, Rulfo, Arguedas, Onetti, García Márquez. Pero la lección es clara: sin novela regionalista no hubiera existido la novela realista cosmopolita.

(Lozano, 1996).

El humor y estrategia escritural, es decir, cómo el autor pone a hablar y jugar a unos personajes vernáculos en su entorno sociocultural y natural, refleja en un relate como En la disestra... rasgos y modos sociopolíticos del habla popular -socio/idiolecto-, casi como una voz cantante de resistencia frente a la voz restrictiva, "unificadora" y anodina, propia de la lengua oficial que propone el centro de la cordillera de los Andes, un coro flemático y reprimido, que reviste un amplio espectro de intereses para estudios que van desde lo antropológico, teatral -la farsa propia de momos heredados del medioevo-, 
hasta lo puramente literario, de hondo sentido poético y humano.

Tomás Carrasquilla inicia este cuento, así: "Este dizque era un hombre que se llamaba Peralta” (Carrasquilla,1958, p. 12). En gaélico -idioma celta hablado en tierras del norte, las dos Irlandas, entre otros), se les denomina ceilidhs a aquellas reuniones propiciadoras o iniciáticas de cantos, relatos y cuentos, comparables y convergentes con nuestras sesiones de entretenimiento rural entorno al fuego -hogar- y, en este caso, circunscritas a las minas de antaño. $\mathrm{Ca}$ rrasquilla cita en sus cartas las famosas sesiones de Peralta, que debían parecerse mucho a una ceilidh.

Lo narrado en este relate proporciona elementos de juicio constructivos y estéticos, más que instructivos o moralizantes, junto con cantos y juegos serios. A este diestro escritor de lo social y lo político de su comarca le interesan: los ritos, las gestas ancestrales, los dichos y refranes -paremiología- y las leyendas populares. La protoliteratura (oralitura) es, en este caso, una fuente viva de la tradición oral, en la que confluyeron negros, blancos e indígenas. Para ilustrar su sociolecto característico del relate en cuestión, leamos a continuación:

Ultimadamente, el documento quería decir que era muy cierto que Peralta le había ganao al Enemigo Malo esa tranquilada de almas con mucha legalidá y en juego muy limpio y muy decente; pero que más sin embargo, esas almas no podían colar al Cielo ni de chiripa, y por eso tenían que quedarse afuera. Pero que, al mismo tiempo, como todas las cosas de Dios tenían remedio, esta cosa se podía arreglar, sin que Peralta ni el Patas se llamaran a engaño. Y el arreglo era asina: que todas las glorias que debían haber ganao esas almas redimidas por Peralta, se ajuntaran en una gloriona grande, y se la metieran enterita a Peralta, que era el que la había ganao con su puño. Y que la cosa del Infierno se arreglaba de esta laya: que esos condenaos no volvían a las penas de las llamas, sino a otro infierno de nuevo uso que valía lo mismo que el de candela. $Y$ era este infierno una indormia muy particular que sacaron de su cabeza el cura y la monjita. Esta indormia dizque era de esta moda: que mi Dios echaba al mundo treinta y tres mil millones de cuerpos, y que a esos cuerpos les metían adentro las almas que sacó Peralta de los profundos infiernos; y que estas almas, manque los taitas de los cuerpos creyeran que eran pal Cielo, ya estaban condenadas desde en vida; $y$ que por eso no les alcanzaba el santo bautismo, porque ya la gracia de mi Dios no les valía, aunque el bautismo fuera de verdá; y que se morían los cuerpos, y volvían las almas a otros, y 
después a otros, y seguía la misma fiesta hasta el día del juicio; que de ai pendelante las ponían a voltiar en rueda en redondo del Ifierno por secula seculórum amén.

(Carrasquilla, 1958, p. 31).

La lúdica, los modos y la génesis de este texto, constituido por unidades léxicas y sémicas propias del dialecto, que el autor ahonda en una fuente excelsa, mediante una selección pluralista de los textos de su memoria emparentada con su pasado como despensero en Argelia de $\mathrm{Ma}-$ ría, y desde la depuración subjetiva y crítica de voces de gran poder preformativo, toma lo aprendido de una perrucha -Teresa Roldán-, y de las otras narradoras orales que visitaban las minas de San Andrés en el mismo corregimiento -Teresas o Rupertas son narradoras de cuentos bien sistematizados como de viejas y niños-, mujeres criollas, mestizas y afrodescendientes enriquecedoras del habla popular de una región susceptible al juego creativo y lúdico.

Así pone de manifiesto un amplio contexto etno-bio-geográfico o, sin siquiera sonar cursi o poco auténtico, el viejo Carrasco erige verosímil y fantásticamente el sabio edificio de una prosa y de ficciones muy sabrosas, que se yerguen por sí solas y sin ambages, con el sabio propósito de complacer a sus lectores y abrigarnos -cuando no em- briagarnos- en las noches oscuras de nuestras almas.

\section{Breve semblanza de Pepe} Mexía: José Félix Mejía Arango (1892-1978)

Caricaturista espléndido, arquitecto y político destacado, le interesó más el servicio público honesto y lo antepuso siempre a sus honorarios. Su tío, Claudino Arango, contrajo matrimonio con Isabel Carrasquilla, hermana única del novelista prodigioso de las breñas de Santo Domingo, con quien surgirá una amistad entrañable hasta la muerte de éste último.

Fundó la revista Panida, con un grupo conformado por Fernando González Ochoa -el filósofo de Viaje a pie-, León de Greiff-Leo Le Gris, Juan Cristóbal, entre sus muchos seudónimos- y Ricardo Rendón, entre otros. Esta revista fue también un grupo vanguardista importante, ejerció gran influencia sobre artistas e intelectuales y tuvo gran relevancia cultural y literaria en la época.

Ilustrador y dibujante a quien el tío de su señora, María, le dedica su Marquesa de Yolombó. Hizo parte de la Vanguardia clandestina (1915-1930), enclavada entre el periodo de dominio de la Academia -Leudo, Pizano, Acevedo-y la aparición de los Bachués, opuestos al 
gramaticalismo de la primera y al discurso panfletario de los segundos.

\section{Figura 1}

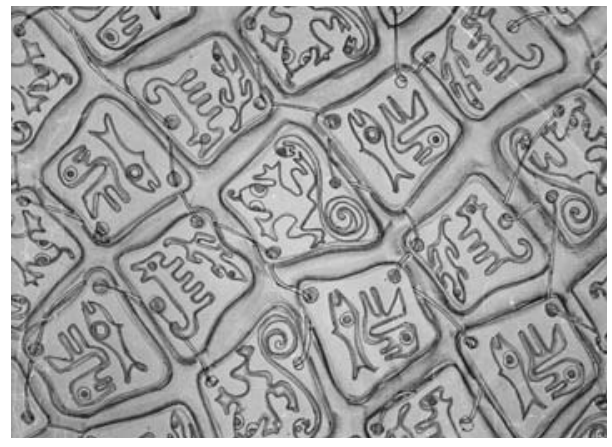

○ Estudio para carátula Núm 4 - Animales

\section{León de Greiff Medellín, 1895 - Bogotá, 1976}

"Menos mal que su espiritu burlón todavia anda por abi desordenando cosas, pues su verdadero oficio en vida fue el de tomapelista".

(Jaramillo, 2005)

León Luis Bogislao von Greiff Haeusler Obregón Rincón -entre otros muchos sus variados seudónimos y sobrenombres epigramáticos: Leo Legrís, Ramón Antigua, Sergio Stepanski- murió de madrugada en su casa del barrio Santa Fe el 11 de julio de 1976.

Se le veía mucho con sus colegas en sitios emblemáticos como El automático, donde Rendón tomó su vida por mano propia una noche tal vez senil y borrascosa. Imaginamos que el poeta jugó ajedrez, fue melómano y lo trasnochaban toda suerte de asuntos mundanos y trasmundanos. Se podían encontrar entre sus bolsillos un pedazo de mojicón o de panela, cual cosianfirulo algo chalado y muy cachaco, otro pisametre, pepo y lechuguino seguidor del Santa Fe.

Imaginamos que estos últimos restos de su dejadez se entremezclaban con algo de picadura, alcoholes no siempre de la mejor calidad y algunos recuerdos de la que no fue su última jugada de ajedrez, así como un centenar de sueños como filones de oro que brotaban de su testa hermosa como hongos y dos pepas zarco-grisáceas, rutilantes e hiperbrillantes: sus ojos.

Vaya impronta la suya, se merece un réquiem para un poeta singularísimo y semilunático. Aquí van dos semblanzas estelares, la de Rendón y la de su poema autobiográfico con todos los visos de su genialidad.

\section{Figura 2}

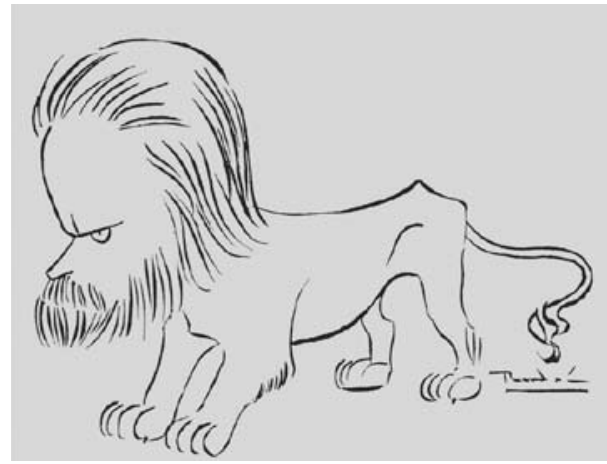

Caricatura por Ricardo Rendón Tomada de: http://www.otraparte.org/actividades/literatura/glosario-leondegreiff.html 
Melenudos de líneas netas, líricos de aires anarquistas, hieráticos anacoretas, dandys, troveros, ensayistas, en fin, sabios o analfabetas, y muy pedantes -si os parece-, exploradores de agrias vetas, ¡los Panidas éramos trece!

León de Greiff fue bachiller del Liceo de la Universidad de Antioquia, cursó tres años de ingeniería en la Escuela de Minas, formó parte del grupo de jóvenes que editó la revista Panida en Medellín, en 1915 y de los que publicaron la revista Los nuevos en Bogotá, en 1925.

Publicó Tergiversaciones (1925), Libro de signos (1930), Variaciones alrededor de nada (1936), Prosa de Gaspar (1937), Fárrago (1954) y Nova et vetera (1973).

Se han hecho tres ediciones de sus obras completas: la primera en $\mathrm{Me}-$ dellín, por la editorial Bedout, en 1960; la segunda en Bogotá, por Tercer Mundo en 1975; y en 1985, Procultura editó la tercera en Bogotá.

En 1986 apareció en Moscú una antología -ciento diecinueve poemas traducidos por Serguei Goncharencointitulada Bajo el signo de Leo. La Universidad de Antioquia publicó en el 2000 una compilación de textos de León de Greiff, bajo el título Obra dispersa de León de Greiff, poesía y prosa y, por su parte, la Universidad Pontificia Bolivariana editó Poemas para sus amigos, en 1995.
Sigamos disfrutando pues de la semblanza de su enhiesta figura, por él mismo:

Si es un retrato mío, aquéste vala: belfa la boca de hastiado gesto si sensual, ojos gríseos, con un resto de su fulgor, -soñantes, de adehala todavía-. La testa sin su gala pilosa. El alta frente. Elato. Enhiesto. El conjunto: mitad Falstaff (si honesto) mitad skalde prófugo de Uppsala.

Hacia el subfondo, el caso lo complico de este jaez: filósofo a la gabe, bufón a lo sarcástico...; ¿poeta?

Poeta..., en ocasiones, aunque imbrico música y poesía, verbo y clave, dolor y burla, rictus y pirueta (de Greiff, 1944, p. 119) 


\section{Sonecillo}

"I only want to ramble

-Listless, wayfarer- as some old personage (say Thor)

Oh or just like drunkard super-tramps... bygones and long-forgotten

To ramble, to roam, in a pennyless, and meaningless new old fashion" ${ }^{4}$

Yo quiero sólo andar, errar-viandante,

indiferente- andar, errar sin rumbo.

¿A qué buscas inútiles, efímeras tensiones

Fatigadas, que anublan las sienes serenas?

Errar, andar, discurrir abstraído:

-vaga lumbre estelar, luz lancinante

del sol, negrura densa de las noches cegadas

sobre mi frente en fuga de varias ficciones-.

Yo sólo quiero andar, errar indiferente,

a caza de ninguna cosa, ni del olvido:

¿A qué buscar olvido? -Buscar ninguna cosa:

vaguear, discurrir por las llanuras desoladas,

por los fragosos riscos, sobre el mar inasible,

para dejar atrás la línea evanescente

del horizonte, sólo: que lo demás es vano

-sueños ilusos, vacuo miraje, sombra veleidosa-.

Yo quiero sólo andar, errar, señero

Baladino, al azar, al capricho ineludible.

¿Qué me dice la túrbida canción de las sirenas?

-¡Bah! Su perfume el viento se llevó de la mano...

$\mathrm{Ni}$ el embaidor arrullo muelle de su cintura

donde abrevé mis ávidas sedes de marinero.

$\mathrm{Ni}$ el fulgor de ojos rútilos que otro instante se opacan.

$\mathrm{Ni}$ el besar bocas róseas en ese instante apenas. 
Yo sólo quiero andar, errar, al impulso moroso

Del fugitivo viento que a todora perdura.

¿Qué me cuentan las noches, ni qué los pálidos días?

- En la noche, por su silencio frío, los titilantes orbes se destacan.

Ambular, discurrir, vaguear

En un lento ritmo, por las llanuras en reposo.

¿Qué me dice la tibia cantiga de las donas?

-Palabras sin perfume. Música blanda.

Cráteras vacías.

Yo sólo quiero andar, errar,-viandante

indiferente-, andar, errar de la mano del viento...

¿A qué seguir el vuelo obscuro de vagabunda saeta, ni de nubes huyentes, ni de valkirias amazonas?

Errar, andar, discurrir abstraído:

-Luz de los orbes, trémula, clara luz lancinante

del sol; negrura sorda de las noches cegadas

sobre mi soledad cogitabunda.

Figura 3
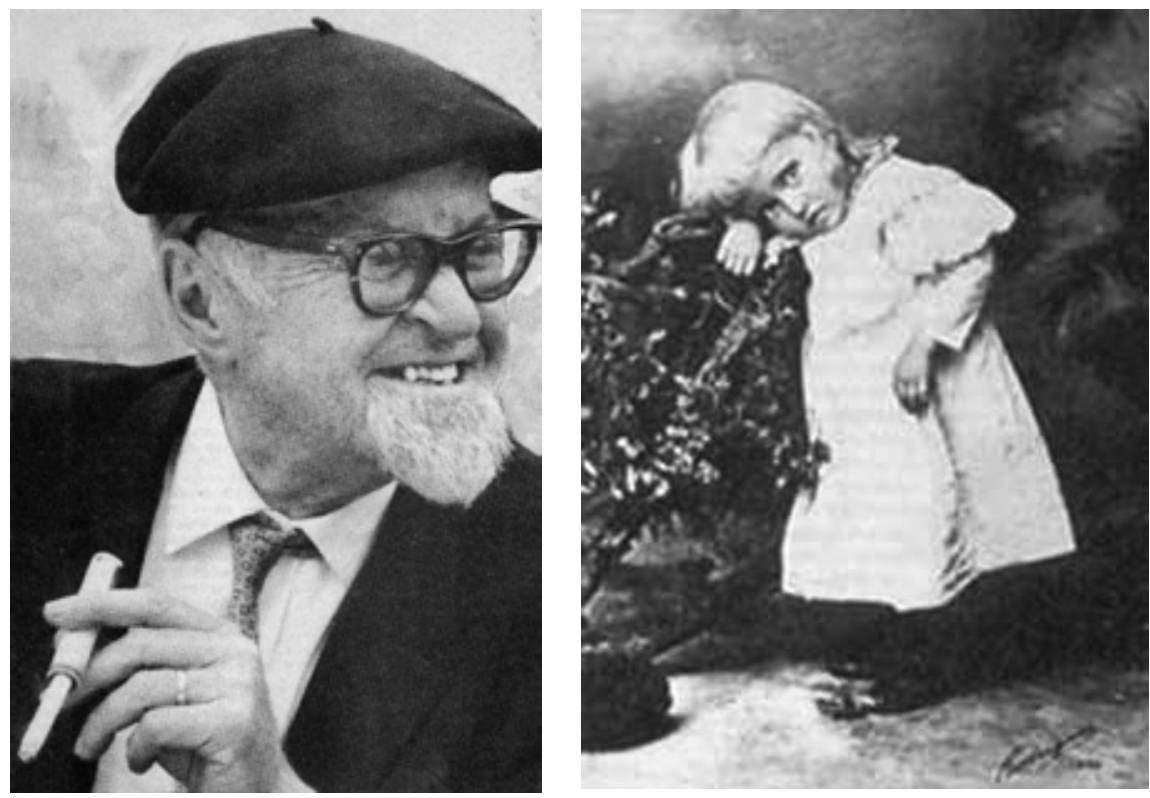

Tomado de: Alvarado, H. Ajuste de cuentas: una antología crítica de la poesía colombiana del siglo XX. Recuperado el 12 de marzo de 2010 desde http://www.antologiacriticadelapoesiacolombiana.com/imagenes/leon_de_greiffgrande.jpg 


\section{Catálogo de obras}

\section{Retratos}

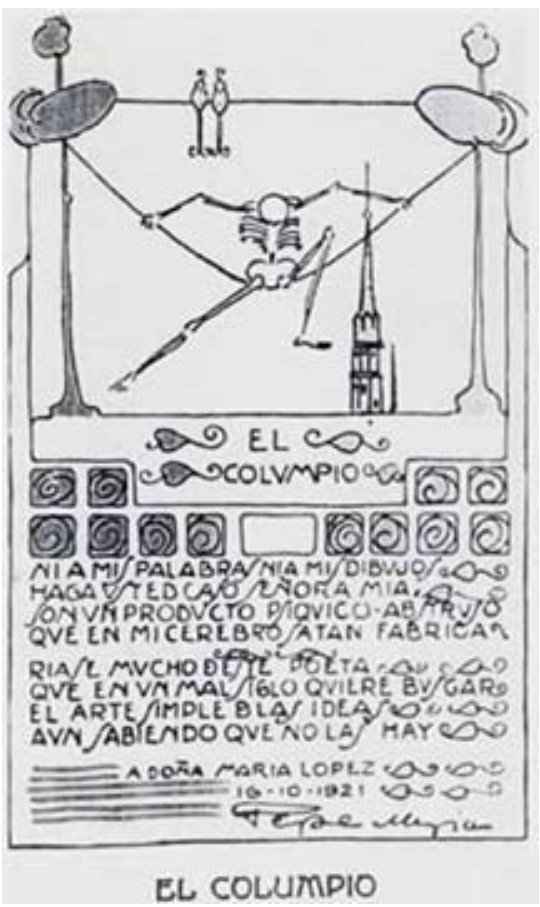

1 Retrato Núm. 1

(Gandhi)

Sin fecha

Lápiz sobre papel

$27,3 \times 21,3 \mathrm{~cm}$

2 Retrato Núm. 4

(James Joyce)

Sin fecha

Lápiz sobre papel $21 \times 28 \mathrm{~cm}$
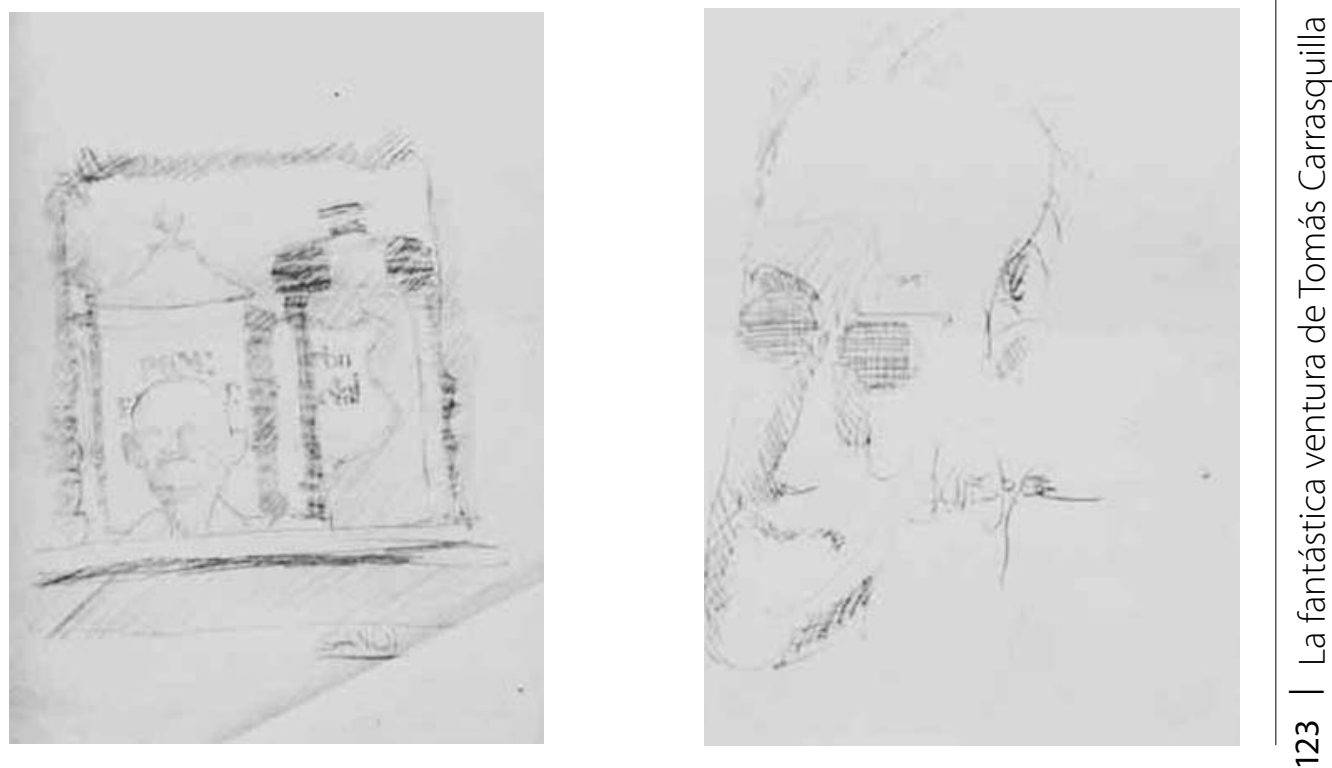


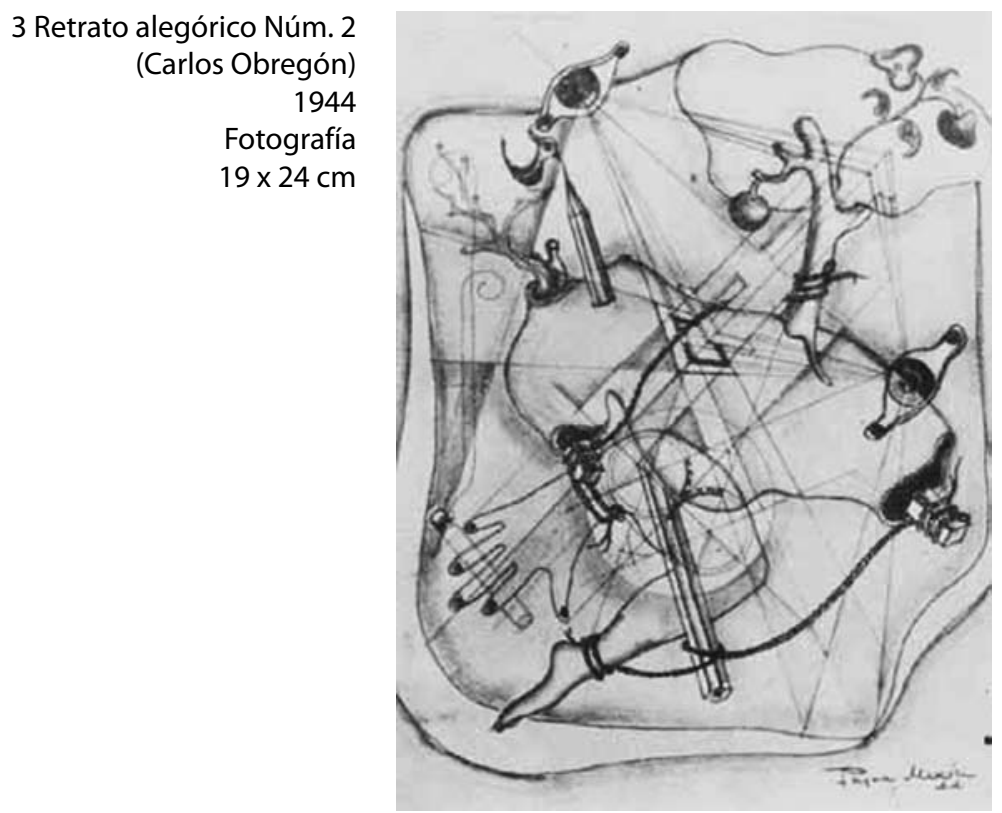

4 Retrato alegórico Núm. 4 (¿Fernando González?) Sin fecha Lápiz de color y tinto sobre papel $22 \times 28 \mathrm{~cm}$

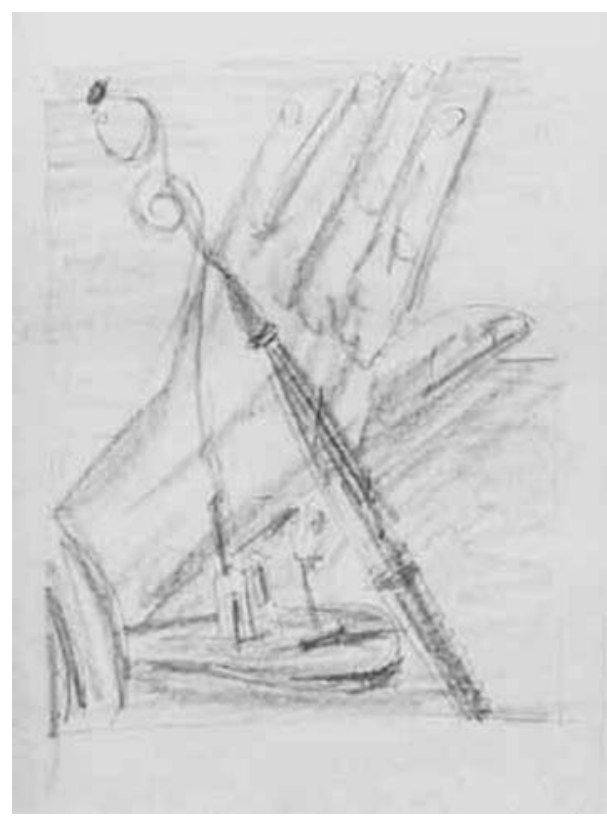


5 Retrato Núm. 9

(Tomás Carrasquilla)

Sin fecha

Lápiz sobre papel mantequilla

$21 \times 28 \mathrm{~cm}$

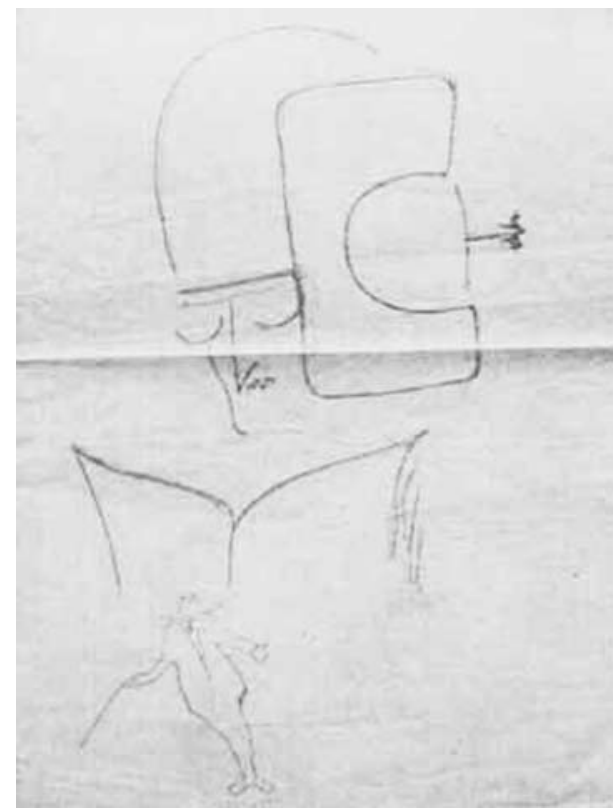

6 Retrato alegórico Núm. 5

(Ciro Mendía)

Sin fecha

Acuarela sobre papel

$18 \times 27 \mathrm{~cm}$

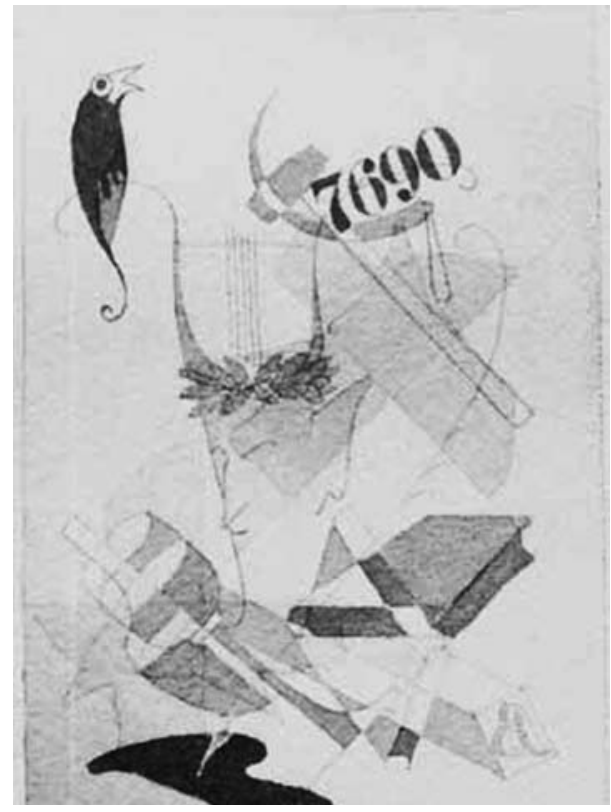


7 Retrato alegórico Núm. 6 (Ignacio Gómez Jaramillo) Sin fecha Lápiz de color sobre papel $22 \times 28 \mathrm{~cm}$

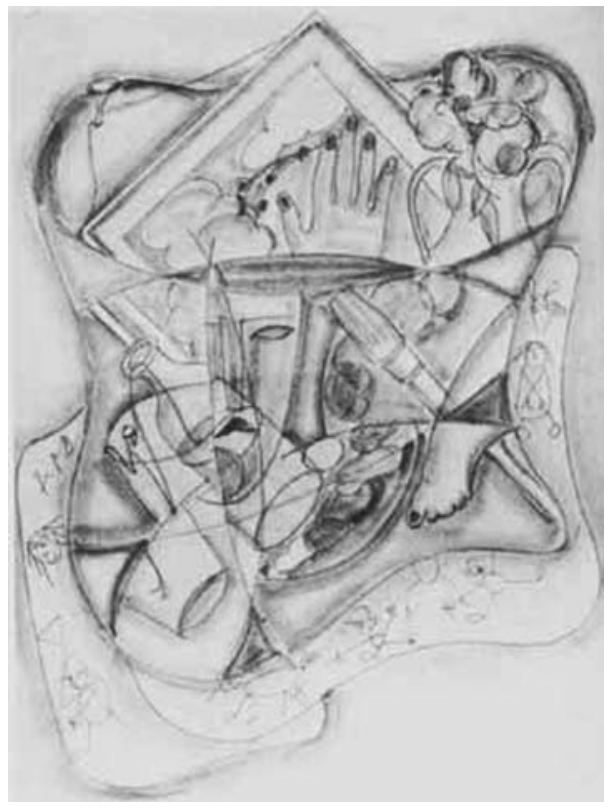

8 Composición abstracta Núm. 19

(José Mejía)

1948

Tinta sobre papel $17 \times 22 \mathrm{~cm}$

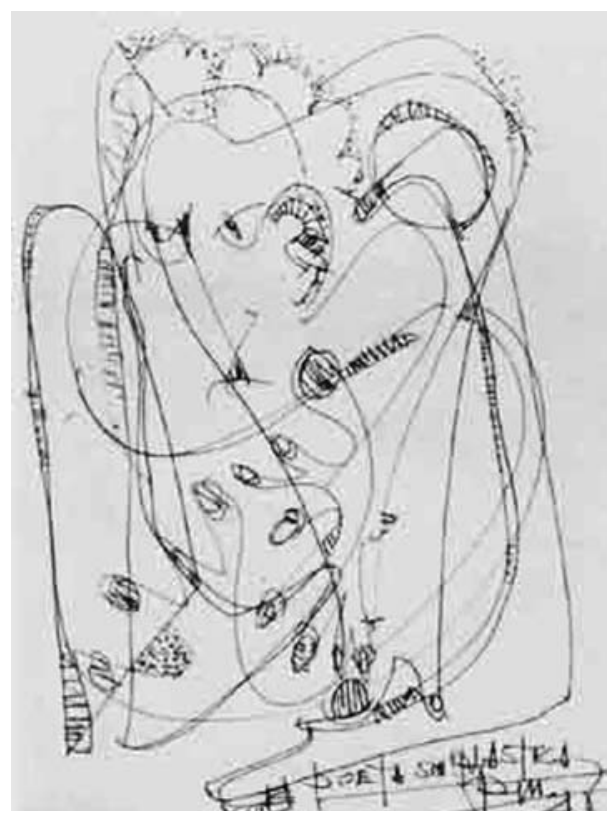


9 Composición figurativa Núm. 9

$$
\begin{array}{r}
\text { (León de Greiff) } \\
\text { Sin fecha }
\end{array}
$$

Tinta sobre papel

$21 \times 28 \mathrm{~cm}$

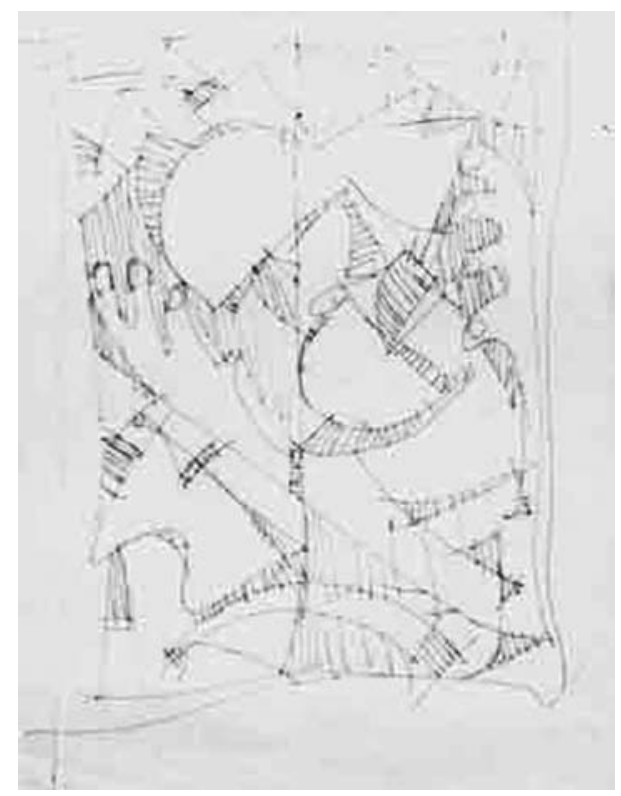

10 Retrato Núm. 3 (¿Autorretrato?)

Sin fecha

tinta sobre papel

$22 \times 28 \mathrm{~cm}$

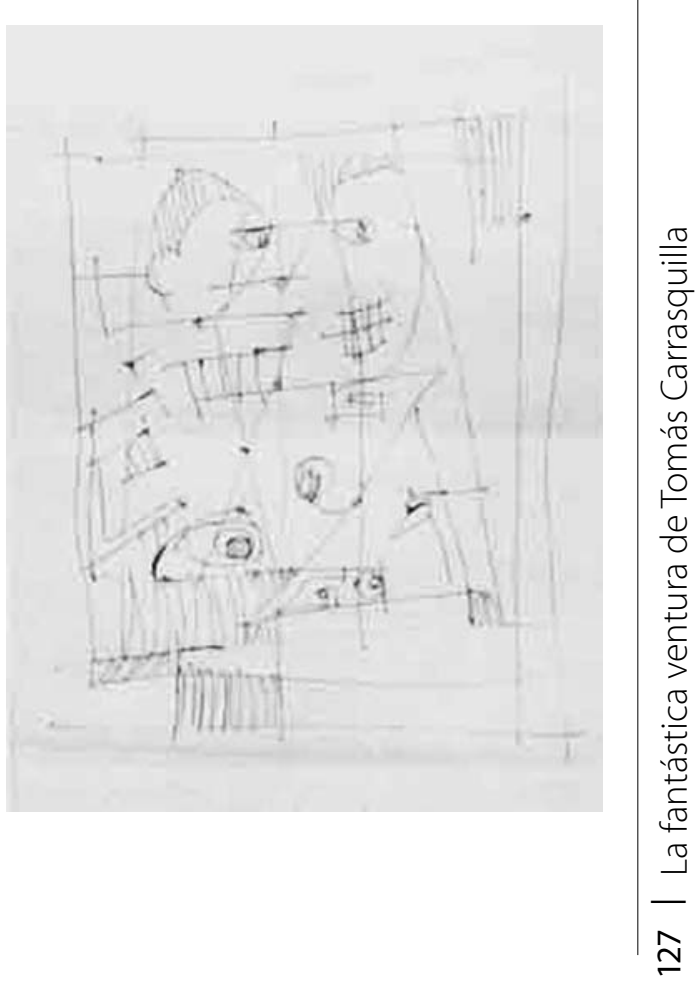




\section{Referencias}

1. Betancur,Á.yLondoño,B.(1995). Estudio semiótico de En la diestra de Dios Padre Tomás Carrasquilla. Medellín: Universidad de Antioquia.

2. Buenaventura, E. (1977). Teatro. Bogotá: Biblioteca Instituto Colombiano de Cultura.

3. Carrasquilla, T. (1952). Obras completas. Madrid: EPASA.

4. (1958). Obras Completas.

Medellín: Bedout.

5. Chevalier, M. (1999). Cuento Tradicional, Cultura, Literatura (Siglos XVI-XIX). Salamanca: Universidad de Salamanca.

6. Corominas, J. (1967). Breve diccionario etimológico de la lengua castellana. Madrid: Gredos.

7. Covarrubias, J. (1987). Tesoro de la lengua española o castellana.

8. Cuervo, R.J. (1954). Prólogo de la primera edición de las Apuntaciones críticas sobre el lenguaje bogotano. Rufino José Cuervo, Obras. p. 6. Bogotá: ICC.

9. DE Greiff, León. (2000). Obra dispersa de León de Greiff, poesía y prosa. Medellín: Editorial Universidad de Antioquia.

10. Flórez, L. (1957). Habla y cultura popular en Antioquia: materiales para un estudio. Publicaciones del Instituto Caro y Cuervo, Núm. 13.

11. González, F. (1999, abril-junio). Hace tiempos de Tomás Carrasquilla.
Revista Universidad de Antioquia, Núm. 256, pp. 8 -15.

12. Günther, H. y Reinhold, W. (1993). Nuevo diccionario de americanismos: nuevo diccionario de colombianismos (NDCol). Tomo 1. Bogotá: ICC.

13. Jaramillo, J. (2005). Por qué León de Greiff era así. Recuperado el 30 de noviembre de 2009 desde http:// www.lablaa.org/blaavirtual/publicacionesbanrep/boletin/boletin68/ boculybi20.htm

14. Kavanagh, P.J. (1965). Collected poems. Dublin: Faber.

15. Levy, Kurt L. (1958). Vida y obras de Tomás Carrasquilla, genitor del regionalismo en la literatura hispanoamericana. Medellín: Bedout.

16. Mejía A., Félix. (1987). Biografía de "Pepe Mexía". Historia de la Caricatura en Colombia: 1. "Pepe Mexia", la caricatura en la Historia. pp. 6-8. Bogotá: Banco de la República.

17. Menton, S. (1964). El cuento hispanoamericano. México: Fondo de Cultura Económica.

18. Menton, S. (1964). El cuento hispanoamericano. México: Fondo de Cultura Económica.

19. Naranjo, J.A. y Córdoba, E.M. (Comp.). (1996). Frutos de mi tierra. Textos críticos. Tomo 2. Medellín: Ediciones Autores Antioqueños.

20. Ospina, U. (1983).Léxico popular en la obra de Tomás Carrasquilla. Bogotá: Tercer Mundo. 
21. Pérez, E. (1978) Plantas útiles de Colombia (Tercera redacción muy corregida y aumentada). (4ta Ed.). Bogotá: Litografía Arco.

22. Reiss, W. (1994). Carta fechada en Túquerres, Nariño. 10 de octubre de 1869. Boletín Cultural y Bibliográfico (BanRep.), Núm. 35 (31), p. 86.

23. SÁnchez, C. (1996). Prólogo a Cuentos de Tomás Carrasquilla Naranjo. Recuperado el 15 de agosto de 2008 desde http://www.lablaa. org/blaavirtual/literatura/carrasqu/ carras1.htm

24. Villegas, N. Apuntaciones sobre el babla antioqueña en Carrasquilla. (1986). Biblioteca de Escritores Caldenses. Tomo 2. Manizales: Imprenta Departamental. 